\title{
WUJUD DAN FAKTOR PENYEBAB KESALAHAN PEMAKAIAN BAHASA JAWA KRAMA DAN CARA MEMPRESERVASINYA
}

\author{
THE EVENT AND CAUSES OF ERRORS IN USE OF JAVA KRAMA \\ AND HOW TO PRESERVE THEM
}

\author{
Pranowoa; Benedictus Bherman Dwijatmoko ${ }^{b}$ Danang Satria Nugrahac \\ a Program Magister Bahasa Indonesia, Universitas Sanata Dharma Yogyakarta. \\ b Program Magister Kajian Bahasa Inggris, Universitas Sanata Dharma, Yogyakarta. \\ c Program Studi Pendidikan Bahasa dan Sastra Indonesia, Unversitas Sanata Dharma. \\ Jalan Affandi 198, Mrican, Demangan, Gondokusuman, Yogyakarta, Indonesia \\ prof.pranowo2021@gmail.com
}

(Naskah diterima tanggal 3 Agustus 2021, direvisi terakhir tanggal 21 Oktober 2021, dan disetujui tanggal 22 November 2021)

DOI: https:/ / doi.org/10.26499/wdprw.v49i2.881

\begin{abstract}
This study discusses "The Form and Factors Causing Errors in Using the Javanese Language of Manners and Cras for Preserving It". This study uses the theory of language relativity to analyze errors in the use of Javanese. Sources of data are students who are in the working environment of researchers. The data is in the form of Javanese speech manners. Data collection techniques are in the form of questionnaires and structured interviews by means of fishing techniques via e-mail or WhatsApp (WA). Data analysis techniques consist of data identification, data classification, and data interpretation. The results of the study are (1) the form of errors in the use of errors in the use of Javanese manners (various types of words and affixes). The causal factor is because (a) they have not been able to distinguish the vocabulary of Javanese krama from Indonesian, (b) have not been able to distinguish the use of Javanese krama for oneself and for parents or other respected people, (c) the Javanese language mastered is limited to "krama ndesa", (d) adjectives that do not have concrete references are a problem in itself, and (e) many of the Javanese krama affixes used are incomplete, (2) the preservation of the Javanese krama language needs to be carried out so that the Javanese krama language remains sustainable. However, there are still some obstacles faced, namely (a) many parents no longer use BJ krama, (b) the younger generation speaks accustomed to using Javanese ngoko or Indonesian, (c) some Javanese language teachers are not from their fields, (e) many BJ teachers are not creative enough, and (f) the younger generation of Javanese who are not good enough get less motivation from their environment.
\end{abstract}

Keywords: language preservation; local wisdom; Javanese's Krama

Abstrak
Penelitian ini membahas “Wujud dan Faktor Penyebab Kesalahan Pemakaian Bahasa Jawa
krama dan Cara Mempreservasinya”. Penelitian menggunakan teori relativitas bahasa un- 
tuk menganalisis kesalahan pemakaian bahasa Jawa. Sumber data adalah para mahasiswa yang berada di lingkungan kerja peneliti. Data berupa tuturan bahasa Jawa krama. Teknik pengumpulan data berupa angket dan wawancara terstruktur dengan cara teknik pancing lewat e-mail atau WhatsApp (WA). Teknik analisis data terdiri atas identifikasi data, klasifikasi data, dan interpretasi data. Hasil penelitian berupa dua temuan. Pertama, wujud kesalahan pemakaian kesalahan pemakaian bahasa Jawa krama pada berbagai jenis kata dan imbuhan). Faktor peyebabnya adalah karena (a) belum mampu membedakan kosakata bahasa Jawa krama dengan bahasa Indonesia, (b) belum dapat membedakan peruntukan bahasa Jawa krama untuk diri sendiri dan untuk orang tua atau orang lain yang dihormati, (c) bahasa Jawa yang dikuasai terbatas pada "krama ndesa", (d) kata sifat yang tidak memiliki acuan konkret menjadi kesulitan tersendiri, dan (e) banyak imbuhan bahasa Jawa krama yang dipakai tidak lengkap. Kedua, preservasi bahasa Jawa krama yang perlu terus dilakukan agar bahasa Jawa krama tetap lestari. Namun masih terdapat beberapa kendala yang dihadapi, yaitu (a) banyak orang tua tidak lagi menggunakan BJ krama, (b) generasi muda bertutur terbiasa menggunakan bahasa Jawa ngoko atau bahasa Indonesia, (c) sebagian guru bahasa Jawa bukan dari bidangnya, (e) banyak guru BJ yang kurang kreatif, dan (f) bahasa Jawa generasi muda yang belum baik kurang mendapat motivasi dari lingkungannya.

Kata-kata kunci: preservasi; kearifan local; bahasa Jawa krama

\section{Pendahuluan}

Teori relativitas bahasa dan relativitas budaya sebagai literatur klasik pernah dikemukakan oleh Sapir (Sapir 1921). Worf sebagai mahasiswa Sapir, mengikuti jalan pikiran Sapir bahwa bahasa itu bersifat relatif. Hipotesis Sapir-Whorf lebih tegas menyatakan bahwa struktur bahasa yang digunakan secara terus-menerus mem pengaruhi cara seseorang berpikir dan berperilaku. Bahasa dapat dikatakan sebagai bagian integral dari manusia- bahasa menyerap setiap pikiran dan bagaimana cara penutur memandang dunianya. $\mathrm{Hu}-$ bungan bahasa, kebudayaan, dan pikiran merupakan dasar relativitas berdasarkan teori Sapir (Kadarisman 2005: 152-170); ((Tohidian 2008)(Newman 2015)((Danesi 2021) ((Hodžić-Čavkić 2021): 75-94); ((Hinton 2021): 15); (Fraissler 2021): 35). Menurut Sapir, perbedaan antarbahasa terjadi karena perbedaan cara mengungkapkan pengalaman manusia, bukan kare- na perbedaan pengalaman itu sendiri. Bahasa dapat dikatakan sebagai bagian integral dari manusia, bahasa menyerap setiap pikiran dan cara penuturnya memandang dunia (Wahab; 1995: 87); (Vladimirovich 2021) Mondal, 2021:23). Worf sebagai murid Sapir menyimpulkan bahwa pe-rilaku budaya manusia dapat dibentuk oleh bahasa. Bukti bahwa bahasa membentuk perilaku manusia seperti perilaku manusia yang terjadi di tempat mereka bekerja.

Di lingkungan kita, peringatan seperti itu juga dapat ditemui pada rambu-rambu lalu lintas di jalan dengan berbagai bentuk bahasa, ada yang verbal dan ada pula yang nonverbal. Kita dapat melihat ramburambu di sekitar jalan kampung kita. Ada rambu bertuliskan "dilarang ngebut, banyak anak kecil!". Bagi pengendara mobil atau motor yang mengendarai kendaraan dan membaca tulisan seperti itu kemudian mengurangi kecepatan kendaraannya 
(Yule, 1983: 67); ((Overstreet and Yule 2002). Hal yang sama terjadi pada ramburambu lain di jalan dengan bahasa nonverbal statis seperti (2) (8) (1) yang bermakna 'dilarang parkir', 'dilarang lewat', 'dilarang putar balik arah', 'dilarang berbelok' telah menjadi aturan konvensional yang ditaati oleh semua orang, kecuali orang yang "tidak waras".

Perilaku bahasa menunjukkan budaya masyarakat. Hal seperti itu juga terjadi pada bahasa Jawa (BJ) krama. BJ sebagai bahasa daerah selalu dihargai oleh masyarakaat Jawa. Mereka berpandangan bahwa BJ memiliki kearifaan lokal yang bernilai luhur dan dipelihara secara baik oleh masyarakatnya. Kearifan lokal adalah identitas kepribadian dan pandangan hidup yang tertanam dalam masyarakat suatu bangsa yang diwariskan secara turuntemurun karena diyakini memiliki nilai luhur. BJ krama menentukan budaya masyarakat Jawa yang dapat menentukan perilakunya. Ungkapan verbal 'matur nuwun' (terima kasih) disertai bahasa nonverbal "posisi badan agak membungkuk", "sumangga" (silakan) disertai dengan menjulurkan tangan kanan", "ndherek lang-kung" (ikut lewat) "sambil menunduk dan tangan berposisi lurus dan menempel paha", dan "nyuwun pangapunten" (mohon maaf) "kedua telapak tangan menangkup dan menempel di dada". Hal-hal seperti dipandang sebagai kearifan lokal (KL). KL sudah menjadi pengertian umum yang diartikan sebagai identitas atau kepribadian budaya suatu bangsa yang menyebabkan bangsa tersebut mampu menyerap dan mengolah kebudayaan dari luar/bangsa lain menjadi watak dan kepribadian sendiri. Kearifan lokal dapat diidentifikasi sebagai berikut.

Pertama, BJ krama sebagai KL diwariskan secara turun-temurun yang di da- lam-nya mengandung budaya luhur, seperti sikap rendah hati, bijaksana, empati, dll. Budaya luhur seperti itu tercermin dalam BJ. Tidak ada kandungan budaya yang dapat dilihat selain melalui bahasa, entah bahasa verbal maupun bahasa nonverbal. Tuturan BJ krama seperti "Kita sumanggakaken menawi ingkang dipunkersakaken mekaten" (Kami persilakan jika yang diinginkan seperti itu). Tuturan seperti itu mengandung KL bahwa berdasarkan budayanya, orang Jawa tidak pernah memaksakan kehendak.

Kedua, BJ krama mampu menyesuaikan diri dan mau menyerap kosakata asing tanpa kehilangan kekhasan BJ kramanya, misalnya kata kata "efektif menjadi keefektifannya" diserap dalam BJ krama menjadi 'keefektifanipun'. Begitu juga dengan kata "spoor" (belanda) dalam BJ krama dapat dikatakan menjadi 'sepuripun', "jerrycam" menjadi 'jerigen' dalam BJ krama jerigenipun. Dengan cara seperti itu, BJ krama dapat menerima pengaruh bahasa asing tetapi tidak kehilangan jati dirinya. BJ krama juga mampu menerima perbedaan yang ada pada etnis lain, seperti perbedaan suku, agama, ras, golongan tetapi budaya Jawa sebagai cerminan BJ krama tidak perlu kehilangan sifat-sifat hakiki yang dimilikinya. Orang Jawa selalu memandang bahwa perbedaan adalah kenyataan yang tidak dapat dihindari. Masyarakat Jawa memiliki pegangan sebagai kearifan lokal, seperti "Jika Anda beragama Islam, jadilah orang Islam Indonesia yang baik tetapi tidak menjadi orang Arab. Begitu juga, jika Anda beragama Nasrani, jadilah orang Nasrani Indonesia yang baik tetapi tidak menjadi orang Romawi". Prinsip-prinsip KL seperti itulah yang tetap dipegang oleh masyarakat Jawa.

Ketiga, BJ krama tidak mudah larut dengan budaya lain. Banyak aspek budaya modern yang kadang-kadang selalu bersi- 
fat individualistis yang muncul dalam kosakata bahasa asing (Inggris), BJ tetap adaptif tetapi tidak menjadi individualistis. Misalnya, kata "I" dalam bahasa Inggris tidak serta-merta diaih bahasakan menjadi "aku" tetapi menjadi "dalem". Begitu juga dengan "berkunjung" dalam BJ krama diganti dengan kata "sowan". "Saya mau berkunjung", dalam BJ krama dikatakan "Dalem badhe sowan". Tuturan seperti itu mengandung makna sikap rendah hati sebagai manifestasi kesantunan karena kesantunan budaya yang terlihat secara eksplisit melalui bahasa (Pudjosoedarmo, 1979: 30).

Keempat, BJ krama yang mencerminkan budaya Jawa luhur mengakar sampai sekarang. Pewarisan turuntemurun sudah mengakar sejak nenek moyang. Namun, kadang-kadang tidak semua yang diingat oleh nenek moyang dapat diwariskan kepada generasi berikutnya karena ada yang lupa atau dianggap tidak menarik untuk diwariskan. Dengan demikian, pewarisan BJ perlu disistematisasi kaidah atau pedoman agar dapat memiliki model pewarisan yang lebih baik.

Atas dasar pengertian di atas, bahasa Jawa (BJ) sebagai bahasa etnis Jawa sudah terbukti ratusan tahun mampu bertahan hidup, lestari, adaptif terhadap perubahan, dan mampu mempertahankan jati diri kejawaannya tanpa larut dengan budaya lain sampai sekarang. Oleh karena itu, BJ dapat dikatakan memiliki nilai KL karena masih tetap selaras dengan perkembangan zaman. KL seperti itu merupakan amanah dari leluhur yang harus diterima sebagai warisan dan harus tetap dipreservasi dan dirawat agar tidak rusak atau tidak punah.

Di antara bahasa daerah lain di Nusantara, BJ memiliki jumlah penutur paling banyak yang menyebar hampir di seluruh wilayah Indonesia (Hadi, dkk., 2019: 23). Hal seperti itulah yang menjadikan etnis
Jawa bangga sebagai pemilik BJ, dan etnis lain hormat terhadap masyarakat Jawa karena sikap dan perilakunya terhadap etnis lain selalu bersikap rendah hati, bijaksana, rukun dan hormat kepada orang lain, serta tidak sombong (Budiyono, 2017: 92).

Hal yang perlu dipahami secara komprehensif adalah bahwa BJ krama sebagai bahasa hormat dan santun. Sayangnya, generasi sebelumnya menguasai BJ krama juga hanya secara turun-temurun dan penguasaannya tidak sistematis (Krashen, 2013: 27). Sementara itu, generasi muda (tingkat pendidikan mahasiswa ke bawah) sudah banyak yang tidak mampu ber-BJ krama (Nababan, 2012: 15). Jika memang asumsi, persepsi, dan fakta yang berkembang dalam masyarakat itu benar, perlu dicarikan jalan keluar bagaimana agar BJ krama sebagai kearifan lokal dapat dipreservasi (Budiyono, 201: 92); Wiradimadja, 2018: 1). Asumsi yang mengatakan bahwa selama masyarakat Jawa masih ada, BJ masih tetap ada. Namun, jika asumsinya berkaitan dengan BJ krama, nampaknya asumsi tersebut terlalu percaya diri karena faktanya sudah banyak masyarakat yang tidak mampu ber-BJ krama (Jazeri, dkk., 2019: 22).

Berkaitan dengan hal tersebut, generasi muda sudah banyak yang tidak mampu menggunakan BJ krama. Namun, hal ini tidak berarti BJ krama akan punah jika masyarakat Jawa mau berusaha dan mencari cara agar masih tetap diminati oleh generasi muda. Usaha preservasi BJ krama secara sistematis dikhususkan BJ krama lisan verbal dan nonverbal agar generasi muda tetap mampu berbahasa Jawa krama dengan baik dan benar. Permasalahan utamanya adalah seperti apa sajakah wujud BJ krama dan faktor apa sajakah penyebab kesalahan pemakaian wujud BJ krama dan cara mempreservasinya untuk generasi muda? Submasalahnya adalah (a) 
seperti apakah wujud BJ krama dan faktor penyebab kesalahan pemakaian para generasi muda dewasa ini?, dan (b) bagaimana cara mempreservasi BJ krama agar generasi muda tetap mampu memakainya?

\section{Metode Penelitian}

Penelitian ini merupakan penelitian studi kasus yang bersifat deskriptif kualitatif. Studi kasus adalah metode yang bertujuan untuk mempelajari suatu kejadian atau fenomena mengenai individu yang menjadi objek penelitian. Studi kasus dalam penelitian ini adalah mahasiswa yang berasal dari masyarakat Jawa sebagai responden. Secara umum, penelitian kualitatif merupakan penelitian yang berpegang pada paradigma naturalistik dan fenomenalogis. Artinya, penelitian kualitatif dilakukan dalam setting alamiah dan penelitian berangkat dari fenomena yang ada. Ciri-ciri utama penelitian kualitatif, yaitu peneliti terlibat langsung dengan setting sosial penelitian, bersifat deskriptif, menekankan pada proses daripada hasil penelitian.

Analisis dilakukan secara induktif, dan peneliti sebagai istrumen utama. Teori dasar yang digunakan adalah teori Sapir dan Worf yang berkaitan dengan hipotesis relativitas bahasa dan budaya. Pada dasarnya, bahasa mencerminkan kebudayaan masyarakat pemiliknya. Sumber data penelitian adalah pemakai BJ krama yang berada di lingkungan kerja peneliti. Data penelitiannya berupa tuturan mahasiswa yang ingin memiliki kemampuan bertutur BJ krama. Teknik pengumpulan datanya adalah angket dan wawancara yang dikirim melalui e-mail dan WA. Teknik analisis data dilakukan melalui identifikasi data, klasifikasi data, dan interpretasi data. Hasil analisis disajikan secara terstruktur berdasarkan masalah penelitian. Elaborasi deskriptif disajikan sebagai ulasan kritis atas temuan-temuan dalam penelitian ini. Hasil analisisi dibahas berdasarkan teori utama relativitas bahasa dan budaya.

\section{Hasil Penelitian dan Pembahasan}

\subsection{Hasil Penelitian}

\subsubsection{Wujud dan Faktor Penyebab Kesa- lahan Pemakaian BJ Krama}

Wujud atau bentuk bahasa sebagai cermin kebudayaan masyarakat Jawa selaras dengan yang dimaksudkan hipotesis SapirWhorf bahwa struktur bahasa yang digunakan secara terus menerus mempengaruhi cara seseorang berpikir dan berperilaku (Kadarisman, 2005: 152); Wahyono, dkk., 2018: 305). Manifestasi kebudayaan baru dapat dilihat melalui wujud beberapa kesalahan bahasa yang dipakai dan faktor penyebabnya. Berikut dipaparkan beberapa data sebagai wujud kesalahan pemakaian bahasa Jawa krama dan faktor penyebab terjadinya. Sebagai cermin kebudayaan terdapat beberapa fenomena wujud dan faktor kesalahan pemakaian BJ krama, seperti (a) kata benda, (b) kata kerja, (c) kata sifat, (d) kata ganti, (e) kata bilangan, (f) kata tugas, dan ada pula (g) wujud imbuhan dan faktor penyebab terjadinya kesalahan. Oleh karena itu pemakaian bahasa Jawa krama perlu dipreservasi agar tetap lestari atau langgeng di masyarakat Jawa.

Di samping wujud kosakata, juga terdapat data berupa wujud imbuhan BJ ngoko dan BJ krama (Suwaji, 1994: 20); (Rustiati, 2008: 47). Penanda linguistis yang menunjukkan bahwa bahasa sebagai cermin kebudayaan dapat diidentifikasi sebagai berikut.

\section{a. Wujud BJ Krama dan Faktor Penyebab Kesalahan Pemakaian Kata Benda} Wujud kesalahan pemakaian BJ krama terjadi dalam pemakaian kosakata benda terdapat pada data di bawah ini. Kalimat 
yang disusun oleh para responden ternyata banyak yang belum mampu menggunakan kosakata benda BJ krama. Perhatikanlah data (1)-(4) berikut ini.
(1) Pintu griya kula wonten delapan 'Pintu rumah saya ada delapan'
(2) Bapak tumbas celana panjang 'Bapak membeli celana panjang'
(3) Telor bebek kula kathah sanget 'Telor bebek saya banyak sekali'
(4) Jariknya simbah bathik tulis 'Jariknya nenek bathik tulis'

Penanda kesalahan pemakaian kosakata BJ krama terdapat kata "pintu, celana, telor bebek, jarik". Kosakata tersebut salah, seharusnya kosakata yang digunakan adalah "konten, sruwal, tigan, kambangan, dan sinjang". Kata-kata yang belum dapat digunakan dalam BJ krama kemudian diganti dengan kosakata bahasa Indonesia atau bahasa ngoko.

Faktor penyebab terjadinya kesalahan tersebut adalah (i) belum mampu membedakan kosakata BJ krama dengan kosakata bahasa Indonesia, lihat data (1) pintu griya kula wonten delapan, (2) Bapak tumbas celana panjang, (ii) penutur sudah terbiasa menggunakan bahasa Jawa ngoko dalam percakapan sehari-hari, lihat data (3) Telor bebek kula kathah sanget, (4) Jariknya simbah bathik tulis.

\section{b. Wujud dan Faktor Kesalahan Pemakai- an Kata Kerja}

Kosakata kerja BJ krama dalam kehidupan sehari-hari yang seharusnya sudah biasa dipakai. Namun, ternyata juga masih banyak terjadi kesalahan. Wujud kesalahan pemakaian ditemukan dalam data berikut. Kalimat yang disusun oleh responden ternyata banyak yang belum menggunakan kata kerja BJ krama. Perhatikanlah data (5) sampai (8) berikut ini.
(5) Pak lik sampun nedha menapa dereng, kula nembe badhe dhahar.

'Paman sudah makan belum, saya baru akan makan'

(6) Bapak nembe kesah niku pak. Lha badhe ditunggu napa mboten?

'Bapak baru pergi tu, lha akan ditunggu apa tidak?'

(7) Simbah dereng tangi pak, wau dalu "tuguran" ngantos dalu.

'Nenek belum bangun pak, tadi malam lek-lekan sampai malam'

(8) Nuwun sewu, kula badhe siram rumiyin, niki keringetan.

'Mohon maaf, saya mau mandi dulu, ini berkeringat'

Kata-kata yang seharusnya sudah biasa dipakai dalam bahasa Jawa krama alus, penutur salah memilih kata yang seharusnya untuk orang lain justru dipakai untuk diri sendiri, atau sebaliknya, seperti "nedha, dhahar, kesah, ditunggu, tangi, siram". Kata kerja yang seharusnya dipakai untuk orang lain adalah kata dhahar (untuk orang tua atau orang lain yang dihormati), bukan nedha (untuk diri sendiri). Kata kesah adalah kata krama andhap, biasanya untuk diri sendiri dan ditunggu adalah bahasa Indonesia, sedangkan dalam BJ krama seharusnya ditengga. Kata tangi adalah kata ngoko dan tidak cocok untuk orang tua yang seharusnya memakai kata wungu. Begitu juga kata siram adalah bahasa Jawa krama alus yang seharusnya untuk orang tua atau orang lain, justru dipakai untuk diri sendiri.

Kesalahan seperti itu, faktor penyebabnya adalah (i) penutur belum dapat membedakan peruntukan kata kerja krama alus dengan krama andhap lihat data (5) Pak Lik sampun nedha, (6) Bapak nembe kesah, (ii) penutur belum dapat membedakan BJ krama untuk diri sendiri dan untuk orang lain, lihat data (5) kula nembe badhe dhahar, (8) kula badhe siram, (iii) penutur 
belum mengetahui kata bentuk krama, lihat data (6) Lha badhe ditunggu napa mboten, lihat data (7) Simbah dereng tangi, pak, (iv) penutur belum dapat membedakan bentuk krama untuk diri sendiri dan untuk orang lain atauorang yang lebih tua, lihat data (8) ... kula badhe siram rumiyin.

\section{c. Wujud dan Faktor Penyebab Kesala- han Pemakaian Kata Sifat}

Kata sifat ternyata juga masih banyak yang belum benar. Kata sifat yang biasa rujukannya bersifat abstrak ternyata jauh lebih sulit dibandingkan dengan kata benda atau kata kerja. Beberapa data yang digunakan dalam kalimat oleh responden dapat dilihat pada contoh (9) sampai (13) berikut.

(9) Larene dhuwur tur lemu, dados nggih rosa.

'Anaknya tinggi dan gemuk, jadi ya kuat'

(10) Raine niku ireng thuntheng, kula mboten remen.

'Wajahnya itu hitam legam, saya tidak senang'

(11) Dheweke niku masuk angin nika, lha dikeroki gegere abing sedanten.

'Dia itu masuk angin itu, karena dikeroki punggungnya merah semua'

(12) Larene cilik nggih mboten kuwat nek ken mikul kayu ageng.

'Anaknya itu kecil ya tidak kuat kalau disuruh mikul kayu besar'

(13) Manuke niku warnane elik tur mboten nyenengke ngoten tho.

'Burungnya itu warnanya jelek dan tidak menyenangkan gitu lho'.

Wujud kesalahan yang terjadi dapat ditemukan pada data (9) "dhuwur" dan "lemu", (10) "ireng thuntheng", (11) "abing", (12) "cilik", "kuwat", (13) "elik". Wujud keslahan tersebut terdapat pada data (11) $a b$ ing seharusnya abrit, (12) "dhuwur" seharusnya "inggil" dan "lemu" seharusnya "lema". Wujud data (13) "ireng thuntheng" bentuk ngoko. Dalam bahasa Jawa krama seharusnya disebut "cemeng mengesmenges", dan data (14) "abing" bentuk ngoko. Bahasa Jawa krama seharusnya disebut "abret". Wujud data (15) "cilik" "kuwat" juga bentuk ngoko, seharusnya disebut dengan kata "alit" dan "kiyat". Wujud data (16) "elik" adalah wujud bahasa Jawa ngoko yang menyangatkan "elek bangat" seharusnya dalam bajasa Jawa krama dikatakan dengan sebutan "awon sanget".

Faktor penyebab terjadinya kesalahan antara lain (i) tidak diketahuinya wujud kata sifat dalam bahasa Jawa krama, lihat data (9) Larene dhuwur tur lemu, (11) ... lha dikeroki gegere abing sedanten, (12) Larene cilik nggih mboten kuwat nek ken mikul kayu ageng, dan (ii) wujud kata sifat yang menyangatkan juga belum diketahui, lihat data (11) Raine niku ireng thuntheng, kula mboten remen.

\section{d. Wujud dan Faktor Penyebab Kesala- han Pemakaian Kata Ganti}

Kata ganti diri merupakan kata yang dapat menggantikan kata lain sebagai pengganti diri seseorang. Kata ganti diri dapat dilihat contoh (14) - (16) berikut ini.

(14) Mereka badhe sami kesah dhateng Jakarta 'Mereka mau pergi ke Jakarta'

(15) Sampeyan napa mboten sibuk? 'Kamu apa tidak sibuk?'

(16) Kita semua badhe piknik wonten Kali Urang.

'Kita semua akan piknik ke Kali Urang'.

Kata ganti yang sudah biasa dipakai adalah kata ganti orang pertama "kula", kata ganti orang kedua "penjenengan", dan kata ganti orang ketiga "piyambakipun". Kesalahan pemakaian kata ganti orang masih sering terjadi, seperti data (14) "mereka ...sami" dalam kalimat "Mereka badhe sami kesah dhateng Jakarta". Kata 
"mereka" bukan BJ krama tetapi bahasa Indonesia. Kesalahan terjadi pula pada data (15) "sampeyan" dalam kaliat "Sampeyan napa mboten sibuk?". Kata "sampeyan" buan BJ krama alus tetapi krama andhap. Data (16) "kita semua" dalam kalimat "Kita semua badhe piknik wonten Kali Urang". Frasa "kita semua" sebagai kata ganti jamak dalam bahasa Indonesia yang seharusnya dalam bahasa Jawa krama harus dikatakan "kita sedaya".

Faktor yang menjadi penyebab terjadinya kesalahan tersebut adalah (i) penutur belum dapat membedakan kata "piyambakipun" yang berbentuk jamak dan tunggal sehingga penutur memakai kata "mereka" dalam bahasa Indonesia, lihat data (14) Mereka badhe sami kesah dhateng Jakarta, (ii) penutur juga belum dapat membedakan penggunaan kata ganti orang kedua "krama alus" dan "krama andhap". Sebutan untuk orang kedua sebagai bentuk krama alus adalah "penjenengan", bukan "sampeyan", lihat data (15) Sampeyan napa mboten sibuk?, (iii) penutur belum mengetahui bentuk jamak bahasa Jawa krama, lihat data (16) Kita semua badhe piknik wonten Kali Urang.

\section{e. Wujud dan Faktor Kesalahan Pemakai- an Kata Bilangan}

Wujud kosakata bilangan BJ ada yang berbentuk ngoko dan ada pula yang berbentuk krama. Namun, tidak semua kata bilangan ada bentuk kramanya. Wujud kosakata bilangan yang seharusnya ngoko, bagi para penutur yang belum mahir berbahasa Jawa krama, kata bilangan tersebut sering dipaksa untuk diungkapkan dalam bentuk krama sehingga justru menjadi salah. Beberapa tuturan dapat dilihat pada data data (17) dan (20) berikut ini.

(17) Saben tanggal sedasa pitu tentu diadakan upacara)
'Setiap tanggal tujuh belas mesti diadakan upacara bendera'

(18) Jumlah mahasiswanipun wonten kalih dasa wolu

'Jumlah mahasiswanya ada dua puluh delapan'

(19) Cacahipun pring wonten kalih dasa gangsal lonjor

'Jumlah bambunya sebanyak dua puluh lima batang'

(20) Tigang minggu menika wonten kalih dasa setunggal dinten

Berdasarkan data di atas, kata-kata yang dicetak miring seharunya tetap bentuk ngoko yang tidak ada bentuk kramanya. Begitu kata tersebut dikramakan justru menjadi salah dalam bahasa Jawa krama. Data (17) "sedasa pitu" seharusnya "pitulas", data (18) "kalih dasa wolu" seharusnya "wolulikir", data (19) "kalih dasa gangsal" seharusnya "selangkung", dan data (20) "kalih dasa setunggal" seharusnya "selikur".

Faktor penyebab terjadinya kesalahan adalah karena (i) penutur belum dapat membedakan kosakata bilangan mana yang dapat dikramakan dan mana yang harus tetap ngoko. Data nomor 17 sampai nomor 20 menggambarkan hal tersebut, (ii) karena ingin sekali berbahasa Jawa krama, bentuk-bentuk yang seharusnya tetap ngoko justru dikramakan sehingga bentuk kramanya menjadi rancu, data (17) sedasa pitu seharusnya pitulas, (18) data kalih dasa wolu seharusnya wolulas, data (19) kalih dasa gangsal seharusnya selangkung, data (20) kalih dasa setunggal seharusnya selikur.

\section{f. Wujud dan Faktor Kesalahan Pemakai- an Kata Tugas}

Kata tugas dalam BJ krama sebenarnya tidak terlalu sukar. Namun, dalam pemakaiannya juga masih banyak yang belum benar. Kata tugas ini tidak dapat berdiri sendiri karena hanya menjadi penanda ka- 
ta lain. Beberapa data yang ditemukan disajikan dalam kalimat (21)-(26) berikut.

(21) Bapak lan Ibu kesah dhateng Semarang

'Bapak dan Ibu pergi ke Semarang'

(22) Kula tasih alit nalika simbah seda

'Saya masih kecil ketika simbah meninggal'

(23) Awit saka niku, kula mboten saget nyerat Jawa

'Sejak saat itu saya tidak dapat menulis Jawa'

(24)Ajenga kula lare dhusun nggih kepengin sekolah dhuwur

'Meskipun saya anak desa ya ingin sekolah tinggi'

(25) Mbok kula nyuwun peleme nggih, mbah! ‘Mbok saya minta mangganya ya, mbah)!

(26) Nek ngoten niku angsal mboten?

'Jika seperti itu, boleh ndak?'

Wujud kata tugas masih banyak yang belum mampu menggunakan dalam BJ krama secara benar. Kata pada data (21) "lan" (ngoko), kramanya "saha". Kata pada data (22) "nalika" (ngoko), kramanya "rikala". Frasa tugas pada data (23) "awit saka $i k u$ " (ngoko), kramanya "awit saking meni$k a$ ". Data (24) kata "ajenga" (ngoko), kramanya "sinaosa", data (25) pada kata "mbok" (ngoko), dan data (26) "nek" (ngoko) sekedar sebagai kata penegas.

Faktor penyebabnya belum begitu jelas, tetapi ada kemungkinan karena terbiasa berbicara dalam tuturan "krama desa" atau terbiasa "ngoko", dan tidak tahu bentuk krama alus yang harus dipakai.

\section{g. Wujud Imbuhan dan Kesalahan Pema- kaiannya dalam BJ Krama}

BJ memiliki banyak imbuhan, seperti bahasa Indonesia. Namun, data yang ditemukan dari responden hanya beberapa saja yang digunakan dalam tuturan. Imbuhan dalam BJ ngoko ada yang dapat menjadi Imbuan BJ krama tetapi ada pula yang tetap berupa imbuhan BJ ngoko dan yang dikramakan bentuk. Beberapa data disajikan dari nomor (27) - (30) berikut.

(27) Mangga dipundhut piyambak 'Silakan diambil sendiri'

(28) Nyuwun tulung dipunpundhutke gelas 'Minta tolong diambilkan gelas'

(29) Bukune sampun lami 'Bukunya sudah lama'

(30) Menawi ngoten niku dadose nggih salah. 'Jika seperti itu jadinya ya salah'.

Imbuhan BJ dalam data di atas salah pemakaian. Data (27) awalan "di-..." seharusnya "dipun-..." sehingga menjadi "dipunpundhut", data (28) "dipun-...-ke" seharusnya "dipun-...aken" sehinga menjadi dipunpundhutaken, data (29) akhiran "...$n e^{\prime \prime}$ seharusnya "...-ipun" sehingga menjadi bukunipun, dan data (30) "...-e" seharusnya "...-ipun" sehinga menjadi dadosipun .

Faktor yang menyebabkan sedikitnya pemakaian imbuhan dalam BJ krama adalah (i) karena responden belum mengerti imbuhan dalam BJ, baik ngoko maupun krama, (ii) banyak reponden yang belum pernah belajar imbuhan dalam BJ.

Atas dasar hasil analisis tersebut, dapat disajikan dalam bentuk tabel 1 agar mudah dipahami wujud dan faktor penyebab terjadinya kesalahan pemakaian BJ krama.

\subsubsection{Cara Mempreservasi BJ Krama}

Atas dasar analisis wujud dan faktor penyebab kesalahan di atas, para generasi muda (terutama mahasiswa) sebenarnya masih ingin ber-BJ krama, baik untuk berkomunikasi sehari-hari maupun berkomunikasi secara formal. Hal itu sejalan dengan yang dikemukan oleh (Jazeri, et al., 2019: 22) bahwa generasi muda masih ingin menguasai bahasa Ibu tetapi lingkungannya sudah memakai bahasa asing. Hal 
ini dapat dilihat melalui kesalahan berbahasa Jawa yang mereka lakukan. Jika dilihat data kesalahan berbahasa Jawa krama yang digunakan, kesalahan pada pemakaian bahasa dapat dideskripsikan secara ringkas sebagai berikut.

Pertama, responden banyak yang tidak mengetahui bahasa Jawa krama untuk jenis kata benda pada data (1)--(4), seperti kata "pintu, celana, telor bebek, jarik". Katakata tersebut seharusnya dalam bahasa krama menjadi "konten, sruwal, tigan, kambangan, dan sinjang". Kata-kata yang belum dapat digunakan dalam BJ krama kemudian diganti dengan kosakata bahasa Indonesia atau bahasa ngoko.

Kedua, responden banyak yang tidak mengetahui penggunaan kata kerja secara benar untuk diri sendiri atau mitra tutur yang dihadapi seharusnya berbeda. Kata kerja untuk diri sendiri seperti data (5)-(8) seharusnya memakai kata "nedha, tilem, adus, kesah, tangi". Sementara itu, ketika mitra tutur yang dihadapi orang tua atau orang yang dihormati seharusnya menggunakan kata "dhahar, siram, sare, tindak, wungu".

Ketiga, responden banyak yang salah menggunakan kata sifat. Kesalahan penggunaan kata sifat (9) "dhuwur" dan "lemu" seharusnya "inggil" dan "lema", kata sifat (10) "ireng thuntheng" seharusnya "cemeng menges-menges", kata sifat (11) "abing" seharusnya "abrit", kata sifat (12) "cilik", "kuwat" seharusnya "alit" dan "kiyat", kata sifat (13) "elik" seharusnya "awon sanget".

Keempat, kesalahan pemakaian kata ganti orang masih sering terjadi, seperti data (14) "mereka ...sami" dalam kalimat "Mereka badhe sami kesah dhateng Jakarta". Kata "mereka" bukan BJ krama tetapi bahasa Indonesia. Kesalahan terjadi pula pada data (15) "sampeyan" dalam kaliat "Sampeyan napa mboten sibuk?". Kata "sampeyan" bukan BJ krama alus tetapi krama andhap. Data (16) "kita semua" dalam kalimat "Kita semua badhe piknik wonten Kali Urang". Frasa "kita semua" sebagai kata ganti jamak dalam bahasa Indonesia yang seharusnya dalam bahasa Jawa krama seharusnya "kita sedaya".

Kelima, wujud kata tugas masih banyak yang belum mampu menggunakan dalam BJ krama secara benar. Kata tugas pada data (17) "lan" (ngoko), kramanya "saha". Kata pada data (18) "nalika" (ngoko), kramanya "rikala". Frasa tugas pada data (19) "awit saka iku" (ngoko), kramanya "awit saking menika". Data (20) kata "ajenga" (ngoko), kramanya "sinaosa", data (21) pada kata "mbok" (ngoko) dan data (22) "nek" dalam bahasa Jawa sekedar sebagai penegas.

Keenam, banyak kata bilangan yang seharusnya tetap ngoko tetapi justru dikramakan dan justru salah. Data (23) "sedasa pitu" seharusnya "pitulas", data (24) "kalih dasa wolu" seharusnya "wolulas", data (25) "kalih dasa gangsal" seharusnya "selangkung", dan data (26) "kalih dasa setunggal" seharusnya "selikur".

Ketujuh, imbuhan BJ banyak juga yang masih salah dalam pemakaiannya. Data (27) awalan "di-..." seharusnya "dipun-..." sehingga menjadi "dipunpundhut", data (28) "dipun-...-ke" seharusnya "dipun...aken" sehinga menjadi dipunpundhutaken , data (29) akhiran "...-ne" seharusnya "...-ipun" sehingga menjadi bukunipun, dan data (30) "...-e" seharusnya "...-ipun" sehinga menjadi dadosipun .

Dari sekian banyak temuan data di atas, agar dapat dipreservasi perlu diketahui faktor penyebabnya, kemudian dipilih strategi preservasinya. Setiap kesalahan aspek pemakaian bahasa dan kesalahan penggunaan imbuhan diketahui faktor penyebab terjadinya kesalahan. Secara skematis dapat disajikan dalam bentuk tabel berikut. 
Tabel 1

Wujud dan Faktor Terjadinya Kesalahan

\begin{tabular}{ll}
\hline Wujud & \multicolumn{1}{c}{$\begin{array}{c}\text { Faktor Penyebab Terjadinya } \\
\text { Kesalahan }\end{array}$} \\
\hline Kata & - Responden belum mampu mem- \\
benda & bedakan kosakata BJ krama dengan \\
& kosakata bahasa Indonesia \\
& - Responden sudah terbiasa meng- \\
& gunakan bahasa Jawa ngoko dalam \\
& percakapan sehari-hari. \\
Kata ker- & - Responden belum dapat membedakan \\
ja & peruntukan kata kerja krama untuk diri \\
& sendiri dan untuk orang tua atau orang \\
& lain yang dihormati. \\
& - Responden belum mampu mem- \\
& bedakan kata kerja krama andhap \\
& dan krama alus.
\end{tabular}

Kata si- - Respoden belum mengetahui fat bahwa tidak semua kata sifat memiliki acuan yang konkret, se-perti kata "inggil, cilik, kuwat, elik".

- Banyak kata sifat krama yang jarang dipakai dalam bentuk krama. Kalau harus mengatakan kata sifat biasanya diungkapkan menggunakan kata ngoko yang disangatkan,

- Responden terbiasa menggunakan kata sifat dalam bahasa Jawa ngoko atau bahasa Indonesia.

Kata - Kata ganti tertentu jarang dipakai ganti sehingga penutur memakai kata ganti dalam bahasa Indonesia, seperti "kita semua".

Kata bi- - Responden belum dapat membelangan dakan kata bilangan mana yang dapat dikramakan dan mana yang harus tetap ngoko.

- Karena responden ingin sekali berbahasa Jawa krama, bentukbentuk yang seharusnya tetap ngoko justru dikramakan sehingga bentuk kramanya menjadi rancu.

Imbuhan - Karena responden belum mengerti imbuhan dalam BJ, baik ngoko maupun krama

- Banyak reponden yang belum pernah belajar imbuhan dalam BJ.
Setelah diketahui kesalahan pemakaian aspek kebahasaan, kesalahan penggunaan imbuhan, dan faktor penyebab terjadinya kesalahan, masih terdapat kendala untuk menentukan strategi preservasi yang dihadapi oleh generasi muda. Perta$m a$, banyak orang tua mereka tidak lagi menggunakan BJ krama. BJ krama dalam keluarga biasanya hanya untuk berkomunikasi dengan tamu atau orang lain di lingkungan tertentu. Pemahaman orang tua terhadap BJ krama sangat terbatas dan ikut-ikutan ber-BJ ngoko. Berbahasa Jawa dengan anak menggunakan BJ krama bukan "budaya keluarga".

Kedua, ketika generasi muda bertutur dengan teman terbiasa menggunakan BJngoko atau bahasa Indonesia. BJ krama memang hanya biasa digunakan untuk bertutur dengan orang lain yang lebih tua atau orang lain yang kedudukannya lebih tinggi. Hal ini pun tidak dapat dilakukan oleh generasi muda karena memang dalam keluarga tidak berbahasa Jawa krama.

Ketiga, pelajaran BJ krama sebagai muatan lokal hanya 2 jam per minggu. Hal itupun kurang difokuskan pada praktik ber-BJ krama. Padahal, dalam pendekatan komunikatif telah ditekankan bahwa yang terpenting ketika belajar bahasa adalah "bagaimana berbahasa", bukan "apa itu bahasa". Dengan kata lain, BJ krama yang harus dipelajari adalah "bagaimana berbahasa dalam BJ krama" (Ellis, 198: 74); Quinn, 2011: 362).

Keempat, sebagian guru BJ bukan dari bidangnya tetapi dari bidang studi lain sekedar untuk memenuhi kekurangan jam mengajar. Dalam praktiknya mereka mengajarkan BJ menggunakan bahasa Indonesia. Dengan demikian, kemampuan yang dimiliki oleh siswa sama sekali tidak memadai. 
Kelima, banyak guru BJ yang kurang kreatif. Setelah lulus kuliah, mereka ingin mencari pekerjaan dan bukan menciptakan lapangan kerja baru. Padahal, sebenarnya orang yang memiliki kemampuan ber-BJ krama tidak harus dipakai untuk mencari pekerjaan tetapi justru dapat untuk menciptakan lapangan pekerjaan. Pembelajaran bahasa untuk penutur asing sesungguhnya memberikan peluang untuk membuka lapangan pekerjaan. Banyak orang asing yang ingin belajar BJ.

Keenam, sekedar sebagai refleksi, kurikulum Program Studi Bahasa Jawa harus diperbaiki untuk disesuaikan dengan perkembangan teknologi digital yang sekarang sedang booming. BJ krama perlu dipreservasi agar menjadi "monumen hidup" dalam masyarakat. Tolok ukur keberhasilan Program Studi BJ adalah membangun monumen hidup. Ada kemungkinan Program Studi BJ perlu menyesuaikan kurikulum dengan menambahkan salah satu mata kuliah yang mampu memberi peluang kepada lulusannya untuk mempreservasi BJ krama secara audiovisual dalam bentuk pembuatan film pendek sebagai lapangan pekerjaan baru.

Ketujuh, ketika anak-anak muda berusaha ber-BJ krama dengan orang tua di lingkungan masyarakat cenderung ditertawakan dan tidak diapresiasi bahwa mereka sudah berusaha ber-BJ krama. Mereka justru dipersalahkan dan dbunuh motivasinya. Contoh sederhana, anak muda bertutur "Kula sampun dhahar", "Kula badhe sare", "Kula badhe siram" memang BJ krama seperti itu salah. Padahal, jika diberi motivasi secara baik, anak muda yan berusaha ber-BJ krama seperti itu tinggal satu langkah lagi untuk dibenahi BJ kramanya secara benar karena mereka sudah tumbuh motivasi dan sudah ada usaha untuk menguasai BJ krama.
Kedelapan, kongres BJ telah berkali-kali (sudah sampai kongres ke-6) dilakukan tetapi tindak lanjutnya tidak pernah maksimal. Setiap kongres berakhir selalu menghasilkan keputusan namun setelah keputusan dibuat tindak lanjutnya tidak seperti yang diharapkan. Hal ini juga perlu dievaluasi, apakah kongres akan dilanjutkan atau dicari format lain agar hasilnya maksimal.

Karena kondisi seperti itu, beberapa strategi konkret perlu dicari langkah terobosan. Karena masa depan BJ ada di tangan generasi muda, Pertama, mengadakan pelatihan ber-BJ krama di luar lembaga pendidikan. Pelatihan ber-BJ krama dapat dilakukan melalui kerja sama dengan Balai Bahasa setempat atau bergabung dengan kelompok Karang Taruna yang ada di pedesaan. Pelatihan disusun secara praktis khusus melatihkan agar mereka dapat berBJ krama. Aspek-aspek teoretis yang berkaitan dengan kebahasaan (menulis huruf Jawa, atau teori linguistik) biar dipelajari mahasiswa di Program Studi Bahasa Jawa.

Kedua, Balai Bahasa, Dinas Kebudayaan, atau kelompok Karang Taruna sering menyelenggarakan kegiatan ber-BJ krama berupa lomba berpidato (sesorah), bermain sandiwara, atau bermain ketoprak. Kegiatan ini dapat membangkitkan motivasi dan memberikan harapan bahwa BJ krama bukan sekedar untuk "gagahgagahan" tetapi dapat dikembangkan sebagai dasar untuk menciptakan lapangan pekerjaan. Seperti sudah diuraikan di atas, sebenarnya lembaga bahasa swasta banyak yang menyelenggarakan kursus BJ tetapi materinya BJ dialek baku (dialek Yogya atau Solo).

Ketiga, menyelenggarakan lomba menulis dalam BJ krama (apa pun jenis tulisannya, misalnya cerita cekak, novel, sesorah) tetapi mereka diberi penghargaan (apresiasi) uang, bukan sekedar piala. Hal 
ini dimaksudkan untuk memberi motivasi bahwa dengan kemampuan ber-BJ krama dapat memiliki nilai ekonomi yang layak untuk dipelihara.

Keempat, membentuk sanggar-sanggar BJ agar ada mimbar dan atmosfir yang memungkinkan sebagai tempat belajar berBJ. Agar kegiatan ini dapat berlangsung secara terus-menerus, isi kegiatannya bukan sekedar belajar BJ krama tetapi diisi dengan kegiatan lain, seperti membatik, melukis, menatah wayang tetapi ketika berkomunikasi menggunakan BJ krama.

Kelima, sejalan dengan era digital, kegiatan di sanggar selama berlatih ber-BJ krama, juga dilatih membuat video audio visual dan diajari membuat cannal youtube. Hasil kreasi mereka kemudian diunggah di cannal youtube. Dengan langkah terobosan seperti ini, para peserta pelatihan tidak merasa bahwa memiliki kemahiran BJ krama hanya akan mencetak pengangguran. Mereka memiliki tambahan bekal, di samping mahir BJ krama tetapi juga akan mendapat "koin" dan "poin". Koin berarti penghasilan, dan koin berarti prestasi.

\subsection{Pembahasan}

Atas dasar hasil analisis data di atas, ternyata kendala untuk menguasai BJ krama bermacam-macam. Padahal, dalam teori relativitas bahasa, tidak pernah ada kebudayaan tanpa adanya bahasa (Kadarisman, 2005). Oleh karena itu, BJ sebagai kearifan lokal sekaligus merupakan kearifan budaya lokal. Usaha yang dapat dilakukan adalah membuat mimbar baru untuk praktik ber-BJ krama dengan dibimbing oleh instruktur yang sudah terlatih. Model pelatihan ini dibuat berkesinambungan dan dibimbing oleh instruktur yang sudah terlatih.

Generasi muda yang telah memiliki minat, perlu didampingi dan diberi atmosfir yang baik agar mau belajar BJ krama.
Usaha konkret yang harus dilakukan antara lain pembelajaran BJ di sekolah ja-ngan ada guru yang bukan bidangnya lagi. Jika hal ini terus dilakukan, hasilnya justru akan kontra produktif. Materi pelajaraan BJ di sekolah tidak perlu semua diajarkan tetapi difokuskan praktik ber-BJ krama. Hari-hari tertentu, siswa wajib berkomunikasi menggunakan BJ di sekolah. Siswa yang berasal dari daerah lain tetap diwajibkan belajar BJ krama dan ikut praktik BJ krama di hari-hari tertentu.

Seperti dalam teori belajar bahasa pada umumnya, meskipun praktik di luar kelas dapat dikelola seperti di dalam kelas formal. Yang membedakan dengan pembelajaran bahasa di kelas formal dengan di tempat-tempat pelatihan hanyalah atmosfir. Dalam pelatihan, atmosfir kelas dibuat santai seperti pemerolehan bahasa, bukan seperti pembelajaran (Krashen 2013). Model yang perlu dikembangkan adalah seperti yang dimaksud oleh Stevicks. Stevicks menyatakan bahwa suasana pemerolehan dan pembelajaran dapat diintegrasikan karena dalam proses pembelajarpun dapat terjadi proses pemerolehan (Stevicks 1990).

Dalam kaitannya dengan bahasa, artikel ini menggunakan istilah preservasi sebagai usaha untuk menjaga agar bahasa itu tidak rusak entitasnya dan dapat terus berkembang sampai kapanpun. Beberapa usaha yang dapat dilakukan antara lain (a) menjaga agar BJ krama tetap digunakan oleh masyarakat (khususnya) Jawa, (b) menyebarluaskan pemakaiannya di dalam masyarakat, dan (c) menjaga agar tetap berkembang tetapi tidak kehilangan jati dirinya.

\section{Kesimpulan}

Atas dasar hasil analisis dan pembahasan di atas, dapat disimpulkan sebagai berikut. 
Pertama, kesalahan pemakaian bahasa terjadi pada banyak aspek, yaitu (a) kesalahan pemakaian kata benda, (b) kesalahan pemakaian kata kerja, (c) kesalahan pemakaian kata sifat, (d) kesalahan pemakaian kata ganti, (e) kesalahan pemakaian kata bilangan, (f) kesalahan pemakaia kata tugas, dan (g) kesalahan pemakaian imbuhan.

Faktor penyebab terjadinya kesalahan pemakaian tersebut, kendala yang dihadapi oleh generasi muda untuk belajar BJ krama antara lain (a) generasi muda banyak yang belum mampu membedakan kosakata BJ krama dengan kosakata bahasa Indonesia, (b) belum dapat membedakan peruntukkan BJ krama untuk diri sendiri dan untuk orang tua atau orang lain yang dihormati, (c) BJ krama yang dikuasai banyak yang masih terbatas pada " $k r a-$ ma ndesa" dan bukan "krama alus", (d) kata sifat yang tidak memiliki acuan konkret menjadi kesulitan tersendiri bagi mereka, dan (e) kata-kata netral (ngoko dan krama sama saja), sering dipaksakan menjadi bentuk krama. Karena kondisi seperti itu, beberapa strategi konkret perlu dicari langkah terobosan. Karena masa depan BJ ada di tangan generasi muda,

Kedua, preservasi BJ krama perlu terus dilakukan agar BJ krama tetap lestari. Usaha yang harus dilakukan antara lain (a) membangun "monumen hidup" dalam bentuk pelatihan ber-BJ krama melalui lembaga-lembaga pemerintah maupun swasta, (b) dalam proses pelatihan, isi pelatihan bukan sekedar BJ krama tetapi diinternalisasi dengan praktik-praktik berkarya, seperti membatik, menatah wayang, dan lain-lain, (c) agar peserta mampu menciptakan lapangan kerja sendiri, mereka perlu dibekali kemampuan memproduksi film pendek dengan dialog BJ krama.

\section{Daftar Pustaka}

Budiyono, dkk. 2017. "Menggali Nilai Nilai Kearifan Lokal Budaya Jawa sebagai Sumber Pendidikan Karakter." Pp. 92103 in Prosiding SNBK. Madiun.

Danesi, Marcel. 2021. "Linguistic Relativity Today: Language, Mind, Society, and the Foundations of Linguistic Anthropology." Linguistic Relativity Today.

https:// doi.org/10.4324/9781003001669

Ellis, Rod. 1989. “Second Language Learning and Second Language Learners: Growth and Diversity." TESL Canada Journal 7(1):74.

https:/ / doi.org/10.18806/tesl.v7i1.562

Fraissler, Hannes. 2021. “Thought, Language, and Reasoning. Perspectives on the Relation Between Mind and Language." https:// doi.org/10.4013/fsu.2021.221.06

Hadi, Dwi Winanto, Widhi Permanawiyat, Noorman Sambodo, Anisya Oktaviana Anindyatri, and Mas'ad. 2019. Statistik Kebahasaan. Pertama. Jakarta: Kemeenterian Pendidikan dan Kebudayaan, Sekretarian Jendral Pusat Data dan Statistik Pendidikan dan Kebudayaan.

Hinton, Martin. 2021. "Language and Thought." Argumentation Library 37:3-15. https:/ / doi.org/10.1007/978-3-03061694-6_1

Hodžić-Čavkić, $\quad 2021$. "Interdisciplinarity of Sapir-Whorf Hypothesis." Društvene i Humanističke Studije 6(1(14)):75-94. https:/ / doi.org/10.51558/24903647.2021.6.1.75 
Jazeri, Mohamad Jazeri, Dian Nita Zullina, and Siti Zumrotul Maulida. 2019. "Ragam Bahasa Dalam Transaksi JualBeli Di Pasar Beringharjo Yogyakarta." Dialektika: Jurnal Bahasa, Sastra, Dan Pendidikan Bahasa Dan Sastra Indonesia 6(1):22-35. https:/ / doi.org/10.15408/dialektika.v6i 1.9622

Kadarisman, A. Efendi. 2005. "Relatifitas Bahasa Dan Relatifitas Budaya." 232.

Kadarisman, E. Effendi. 2005. "Relatifitas Bahasa Dan Relatifitas Budaya." Linguistik Indonesia tahun 23 V:152-70.

Krashen, Stephen. 2013. Second Lanaguage Acquisition, Theory, Aplication, and Some Conjectures. Newyork: Cambridge University Press.

Mondal, Prakash. 2021. "The Limits of Language-Thought Influences Can Be Set by the Constraints of Embodiment." Frontiers in Psychology 12:593137. https:/ /doi.org/10.3389/fpsyg.2021.593 137

Nababan, Mei Lamria Entalya. 2012. "Kesantunan Veebal Dan Nonverbal Pada Tuturan Direktif Dalam Pembelajaran Di SMP Taman Rama National Plus Jimbaran Mei Lamria." Skripsi.

Newman, John. 2015. “Linguistic Relativity." 174-90. doi: 10.4324/9781315685533-22.

Overstreet, Maryann, and George Yule. 2002. "The Metapragmatics of and Everything." Journal of Pragmatics 34(6):785-94.

https:/ / doi.org/10.1016/S03782166(01)00036-4
Quinn, George. 2011. "Teaching Javanese Respect Usage to Foreign Learners." Electronic Journal of Foreign Language Teaching 8:362-70.

Rustiati. 2008. "Penggunaan Bahasa Jawa Ngoko Dan Krama Di Kalangan Generasi Muda Jawa Di Wilayah Madiun." Universitas Sebelas Maret.

Sapir, Edward. 1921. LLanguage: An Introduction of Speech. Sundiego,New York, Lonndon, Harcout Brace Jovanovich Publishers.

Stevicks, Earl W. 1990. Humanism in Language Teaching.

Suwaji. 1994. Ngoko Lan Krama. Yogyakarta: Yayasan Pustaka Nusantara.

Tohidian, Iman. 2008. "RETRACTED ARTICLE: Examining Linguistic Relativity Hypothesis as One of the Main Views on the Relationship Between Language and Thought." Journal of Psycholinguistic Research 2008 38:1 38(1):65-74.

https:/ / doi.org/10.1007/s10936-0089083-1

Vladimirovich, Popov Dmitry. 2021. "CONCEPT AS A SYNTHESIS OF THE ELEMENTS OF LANGUAGE AND CULTURE." EPRA International Journal of Multidisciplinary Research 7(6):320-25. https:/ / doi.org/10.36713/epra7401

Wahab, Abdul. 1995. Isyu Linguistik: Pengajaran Bahasa Dan Sastra. Surabaya: Airlangga University Press.

Wahyono, Effendi, B. A. B. Ii, Mei Lamria Entalya Nababan, Johana E. Prawitasllri, Sukmawan Wisnu Pradanta, Bani 
Sudardi, Slamet Subiyantoro, A. Kholil, Oleh Sedya Santosa, I. Pengantar, Aris Munandar, Boby Rahman, Ega Selviyanti, Effendi Wahyono, Oleh Moch, Syarif Hidayatullah, Dwi Siswanto, Isbodroini Suyanto-Gunawan, Niken Kusumaningsih, Program Studi, Ilmu Komunikasi, Fakultas Ilmu, Sosial Dan, Universitas Islam, Negeri Sunan, N. C. Sitompul, J1 Walisongo, Ngaliyan Semarang, M. Ridwan, Suharyo Suharyo, Thomas Sixtus Iswahyudi, Bahasa Jawa, Sebagai Simbol, and Budaya Masyarakatnya. 2018. "Stratifikasi Sosial Pada Masyarakat
Pedesaan Di Jawa Abad Ke-19." Seminar Nasional Riset Inovatif 10(2):305-12. https:// doi.org/10.7454/ai.v29i2.3542

Wiradimadja, Agung. 2018. “Kearifan Lokal Masyarakat Kampung Naga sebagai Konservasi Alam dalam Menjaga Budaya Sunda." Jurnal Sosiologi Pendidikan Humanis 3, No. 1:1-8. https://doi.org/10.17977/um021v3i1p1 $-8$

Yule, Gillian Brown \&. George. 1983. Discourse Analysis. Cambridhe University Press. 